\title{
Level of Dental Anxiety and Its Relation to Khat Chewing in Jazan Population: A Cross-sectional Study
}

\author{
Amal K Jumaymi ${ }^{1}$, Wafa H Faqehi ${ }^{2}$, Sabreen A Hamdi ${ }^{3}$, Mohammed B Jarab ${ }^{4}$, Afnan A Essa ${ }^{5}$, Mohammed A Abdulfattah ${ }^{6}$,
} Tariq M Qassadi ${ }^{7}$, Rayid H Alnami ${ }^{8}$, Mohammed M Al Moaleem ${ }^{9}$

\begin{abstract}
Aim: To investigate and compare the levels of dental anxiety (DA) in relation to khat and non-khat chewer subjects of both genders from Jazan subpopulation, Kingdom of Saudi Arabia (KSA).

Materials and methods: A cross-sectional study was conducted to assess DA using the modified dental anxiety scale (MDAS). A total of 352 subjects from the city of Jazan who attended dental clinics for regular treatment were recruited for this study. A questionnaire was used to collect the required information, which consisted of three parts. Descriptive statistics including means, standard deviations, and percentages were calculated. Multiple group comparisons were analyzed using Chi-square tests using the Statistical Package for Social Science (SPSS) program. $p<0.05$ was considered as the significance level.

Results: Among the participants, $75.6 \%$ was male, while $71.3 \%$ khat chewers, and most of them were male (91.2\%). The percentage of the overall mean of MDAS was low; $40 \%$ to moderate; $38 \%$, while sever anxiety were present in $4 \%$ only. Anxiety related to endodontic treatments represents $33.8 \%$ in both genders and $34.3 \%$ among the khat chewers, while fear was $42.1 \%$ among males and $45.4 \%$ among khat chewers. The local anesthesia injection in the gum and tooth drilling items of MDAS were represented by $36.6 \%$ for both khat and gender groups and resulted in a fairly and extremely anxious situation during dental treatments. All variables were significantly different.

Conclusion: The overall DA level was low to moderate among the majority of the assessed subjects. Endodontic treatments were the first type of dental treatments for the subjects, while fear of pain was the most common cause of irregular dental visits. Significant differences were detected between khat and non-khat chewers and between genders in relation to anesthesia injection, and drilling of teeth in the MDAS items. Clinical significance: Community programs focusing on the high DA levels caused by khat chewing might be important in order to minimize the fear of dental treatments and improve and regularize the overall dental treatments.

Keywords: Anxiety scale, Dental anxiety, Gender, Khat.

The Journal of Contemporary Dental Practice (2020): 10.5005/jp-journals-10024-2767
\end{abstract}

\section{INTRODUCTION}

Dental anxiety is known to be an obstacle toward receiving dental treatment. ${ }^{1}$ Dental anxiety can be described as a dental phobia or odontophobia or an aversive emotional state of apprehension or worry in anticipation of the feared stimulus of dental treatment. ${ }^{2}$ Sometimes a more specific term like "dental injection phobia" is used, while some authors link pain with anxiety; but for many patients, DA is not the fear of pain. ${ }^{3}$ In this study, "DA" will be used to refer to all of the above-mentioned terms.

The majority of the studies had measured DA among university students, ${ }^{4-10}$ others evaluated DA among subjects from different population groups. ${ }^{4,5,9,11-16}$ Published studies had registered a low to moderate level of DA in different areas of the world, $, 10,13,14,16-20$ while others found that DA is higher. ${ }^{5,9,12,15,21}$ Researchers recorded that DA is higher among female subjects, ${ }^{5,9-11,14,16-18,20,22}$ while others found it higher among male participants, ${ }^{6,7,13,18}$ still other stated that DA is higher among divorced and low-income ${ }^{13,17}$ or married subjects. ${ }^{23}$

The above-mentioned studies used different scales to measure DA, such as modified dental environmental stress (MDES), Corah's dental anxiety scale (DAS), and modified Corah's dental anxiety scale (MDAS). Norman Corah's dental anxiety scale (NCDAS), dental anxiety question (DAQ), and dental anxiety scale-revised (DAS-R), to assess the level of patient's DA and stress level needed for selected management strategies. The objective measurements of DA can be assessed using MDAS, which is the most popular scale for measuring
${ }^{1}$ Dental Department, Armed Forces Hospitals, Jazan, Kingdom of Saudi Arabia

${ }^{2-4,6}$ College of Dentistry, Jazan University, Jazan, Kingdom of Saudi Arabia

${ }^{5}$ Private Dental Center, Jazan, Kingdom of Saudi Arabia

${ }^{7}$ Dental Department, Aseer Security Forces Specialized Comprehensive Clinics, Abha, Kingdom of Saudi Arabia

${ }^{8}$ Dental Department, Jazan Security Forces Specialized Comprehensive Clinics, Jazan, Kingdom of Saudi Arabia

${ }^{9}$ Department of Prosthetic Dental Science, College of Dentistry, Jazan University, Jazan, Kingdom of Saudi Arabia

Corresponding Author: Mohammed M Al Moaleem, Department of Prosthetic Dental Science, College of Dentistry, Jazan University, Jazan, Kingdom of Saudi Arabia, Phone: +966 550599553, e-mail: drmoaleem2014@gmail.com

How to cite this article: Jumaymi AK, Faqehi WH, Hamdi SA, et al. Level of Dental Anxiety and Its Relation to Khat Chewing in Jazan Population: A Cross-sectional Study. J Contemp Dent Pract 2020;21(3):253-260.

Source of support: Nil

Conflict of interest: None

DA, because of its reliability and validity, and it has excellent psychometric property. ${ }^{24}$ Also, its questionnaire can be answered easily, quickly, and, therefore, it is appropriate for clinical use. ${ }^{25,26}$

Among the items of MDAS, the injection of the local anesthesia in the patients' gum and tooth drilling was the most common causes 
of high $\mathrm{DA},{ }^{5,7,9,15,18,21,22}$ while a single study had mentioned that dental equipment and dental staff items may cause an increase in DA. ${ }^{4}$ Dental treatments such as endodontic treatments, extraction, and dental cost could increase the DA too. ${ }^{5,16}$

Khat (Catha edulis) is an evergreen shrub that belongs to the family Celastraceae. It grows in southern Kingdom of Saudi Arabia as well as in Yemen and many East African countries. Chewing khat acutely elicits the state of euphoria and feeling of wellbeing, which later shift into emotional instability. Khat leaves are masticated during social gatherings, consumed daily, and kept back in buccal vestibule as unilateral or bilateral in the form of bolus for approximately 3-5 hours or more. It grows especially well in moist conditions and is generally cultivated along the mountain slopes at altitudes that varies in height from $3 \mathrm{ft}$ to $15,000 \mathrm{ft}^{27}$

A study on has been published khat-induced psychological problems, though its result seems to be inconsistent. ${ }^{17}$ Yeshaw and Mossie ${ }^{28}$ indicated that being a khat user is one of the predictors of depression, anxiety, and stress. Odenwald et al. ${ }^{29}$ related the psychological effect of khat to its chronic use. Some khat research suggested khat chewing habits are to be associated with depression, anxiety, and stress. .,30 $^{8,3}$

Khat use is usually associated with anxiety and a higher rate of symptoms of depression and stress among female students. ${ }^{17}$ Anxiety and its related dental procedures are one of the frequent problems frequently experienced by most of the Saudi patients. Despite the innovations in dental materials, technologies, and improved knowledge, a significant percentage of patients suffer from DA, which is rated as fourth among common fears and ninth among intense fears. ${ }^{31}$

A group of local studies was done in different areas of Kingdom of Saudi Arabia and in different universities, teaching schools, private clinics, and outpatient's clinics of many governmental hospitals. Few studies were done in Jazan, ${ }^{17,18,21}$ but no previous studies have been conducted to explore the association between DA and khat-chewing habit among subjects. Thus, the current study was designed to investigate and compare the levels of DA among khat and non-khat chewers of both genders from Jazan subpopulation/provenance, Kingdom of Saudi Arabia.

\section{Materials and Methods}

The sample size of about 350 subjects was determined based on G*Power software (http://www.gpower.hhu.de/en.html), with a confidence level adjusted at $95 \%$, power adjusted at $80 \%$, and a moderate effect size. A total of 352 subjects were recruited through nonprobability convenience sampling and selected anonymously and voluntarily. An ethical approval was obtained by the evidencebased research committee, AFJH \# July/10/2019. A survey research was used to gather information in relation to our variable.

Subjects were selected from both genders who were above 18 years of age, medically fit, khat and non-khat chewers, and received regular dental treatments in different dental clinics in Jazan. Participants with any medical disease including mental problems or undergoing medical treatments that might affect their ability to understand the examination sheet were excluded from the study. Subjects who have been chewing khat twice a week for a minimum of 3 years or more were considered as a khat chewers. ${ }^{32}$ The data were collected by three general practitioner dentists who were trained on using the predesigned questionnaire sheet. The subjects were collected from different clinics in Jazan city, namely, governmental, private, and military hospital clinics.
The subjects were met during their regular dental visits. The aims of this study were discussed with the participated subjects and then a consent was signed. Subjects were informed that they have the right to withdraw from the study at any point in time without any consequence and reason.

The questionnaire consisted of three parts (presented as the appendix). The first part focused on personal and demographical data where it included the following: subject's gender, frequency of khat chewing, educational level, monthly income, and marital status. The second part covers the dental history and consisted of three questions, namely, the type of first-time dental treatment, causes of irregular dental visits, and question about that aspects that make the participant anxious? While the third part was related to MDAS which is considered as the most valid and reliable measurement tool used to assess the levels of DA among subjects. ${ }^{14,33}$ It tested participants' anxiety based on certain dental procedures and situations. In the current study, the Arabic version of the MDAS was used to assess the DA as done by Al-Namankany et al. and Al-Nasser et al. ${ }^{34,35}$ This scale consists of a basic of five questions or items and mainly deals with the subjects' feeling during each of the following situation? (1) If you were going to your dentist for treatment tomorrow, (2) if you were sitting in the waiting room, (3) if you were about to have a tooth drilled, (4) if you were about to have your teeth scaled and polished, and (5) if you were about to have a local anesthetic injection in your gum. Each question has five responses scoring from 1 to 5 as (not anxious, slightly anxious, fairly anxious, anxious, and extremely anxious), respectively. The MDAS score is the sum of the five responses and can range from 5 to 25. 4,5,10,16,23,33 A score below 5 was considered as low or not anxious, 5-11 was considered as moderate anxious, 12-18 high anxious, but score of 19 or above was considered as severe dentally anxious or at the border of phobia.

The data were collected and entered into the computer using an Excel sheet (Office 2010) and then Statistical Package for Social Science (SPSS), version 21 (SPSS Inc., Chicago, IL) was used for statistical analysis. Cross tabulations were used to determine the descriptive statistics including means, standard deviation, and percentages for genders, khat chewing habit, marital status, level of education, monthly income, and previous dental treatment experiences. Multiple group comparisons between khat and nonkhat chewers among the two gender groups were analyzed using the Chi-square tests. $p<0.05$ was considered as the significance level.

\section{Results}

Table 1 provides descriptive statistics of the subjects recruited in this study, which were genders, khat chewing, marital status, educational level, and the monthly income. It included 352 subjects, $266(75.6 \%)$ were males and 86 (24.4\%) were females. The highest frequency and percentage, respectively, of the participants were among khat chewers 251 and 71.3, married subjects 273 and 77.6, high school education 161 and 45.7, and the monthly income 144 and 40.9 between 10,000 and 20,000 Saudi Riyal, others 124 and 35.2 were with university/higher diploma certificate, and 20 and 5.7 were divorced.

The mean MDAS score of the subjects was 139 (40\%) followed by $133(38 \%)$ categorized as having a low and moderate levels of DA, respectively. In addition, only $65(18 \%)$ and $15(4 \%)$ of the screened subjects were categorized as high and severe levels of DA (Fig. 1). Dental phobia is recorded as $8.1 \%$ (Fig. 2). 
Table 1: Descriptive distribution of the subjects according to personal and demographic data

\begin{tabular}{|c|c|c|c|c|c|}
\hline Variable & Subgroup & Number ( $n)$ & Percentage & Mean & $\begin{array}{l}\text { Standard } \\
\text { deviation }\end{array}$ \\
\hline \multirow[t]{2}{*}{ Genders } & Males & 266 & 75.6 & 1.24 & 0.480 \\
\hline & Females & 86 & 24.4 & & \\
\hline \multirow[t]{2}{*}{ Khat chewing } & Yes & 251 & 71.3 & 1.29 & 0.453 \\
\hline & No & 101 & 28.7 & & \\
\hline \multirow[t]{3}{*}{ Marital status } & Single & 59 & 16.8 & 1.89 & 0.461 \\
\hline & Married & 273 & 77.6 & & \\
\hline & Divorced & 20 & 5.7 & & \\
\hline \multirow[t]{4}{*}{ Educational level } & Non-educated & 62 & 17.6 & 2.20 & 0.738 \\
\hline & High school & 161 & 45.7 & & \\
\hline & University/high diploma & 124 & 35.2 & & \\
\hline & Post-graduate & 5 & 1.4 & & \\
\hline \multirow[t]{4}{*}{ Monthly income } & Up to 3,000 & 89 & 25.3 & 2.23 & 0.871 \\
\hline & Between 3,000-10,000 & 106 & 30.1 & & \\
\hline & Between 10,000-20,000 & 144 & 40.9 & & \\
\hline & More than $\geq 20,000$ & 13 & 3.7 & & \\
\hline
\end{tabular}

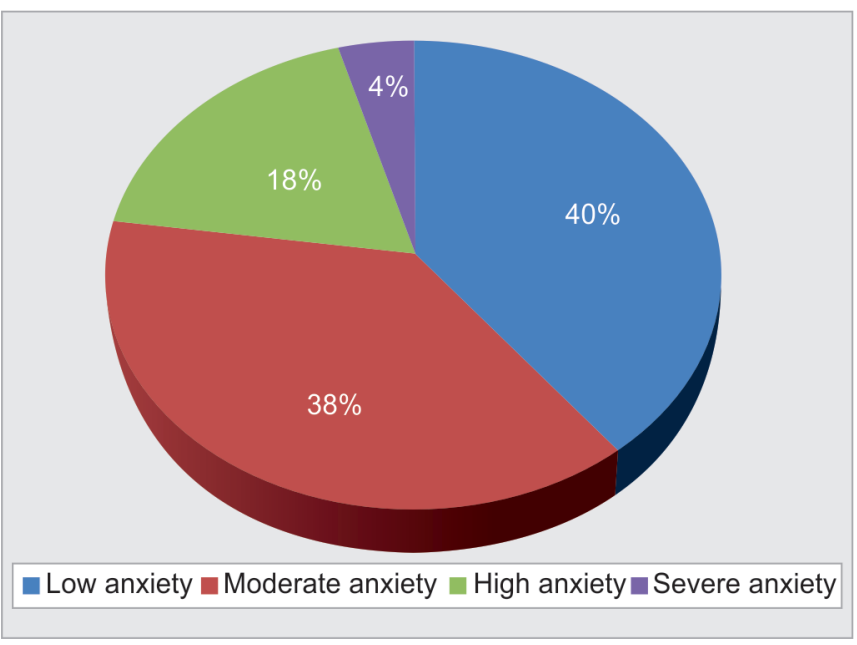

Fig. 1: Distribution of anxiety levels among subjects participants $(n=$ 352)
The association between genders and the type of dental treatment at the first dental visit was significant with $p$ value 0.000 (Table 2). Among male subjects, the highest was at endodontic treatment, followed by periodontal and surgical treatments and recorded as $33.8 \%, 25.2 \%$, and $22.9 \%$, respectively. But for female subjects, the highest was during prosthodontic and orthodontics followed by surgery and represented by $25.4 \%$ and $23.3 \%$, respectively. The highest percentage of irregular dental visits were due to fear in both genders, i.e., 42.1 males and 32.6 females with a significant $p$ value of 0.013 . The association between gender and what makes the patient anxious was not significant ( $p$ value 0.197), with a highest percentage related to the local anesthesia injection and recorded as 42.1 for males and $40.7 \%$ females, but the lowest was related to the fear of pain among male (27.8) and female (33.7).

The correlation between khat chewing and the type of dental treatment at the first dental visit was significant with $p$ value of 0.000 . In relation to the type of the first dental treatment, among khat chewer subjects, the highest was at endodontic treatment

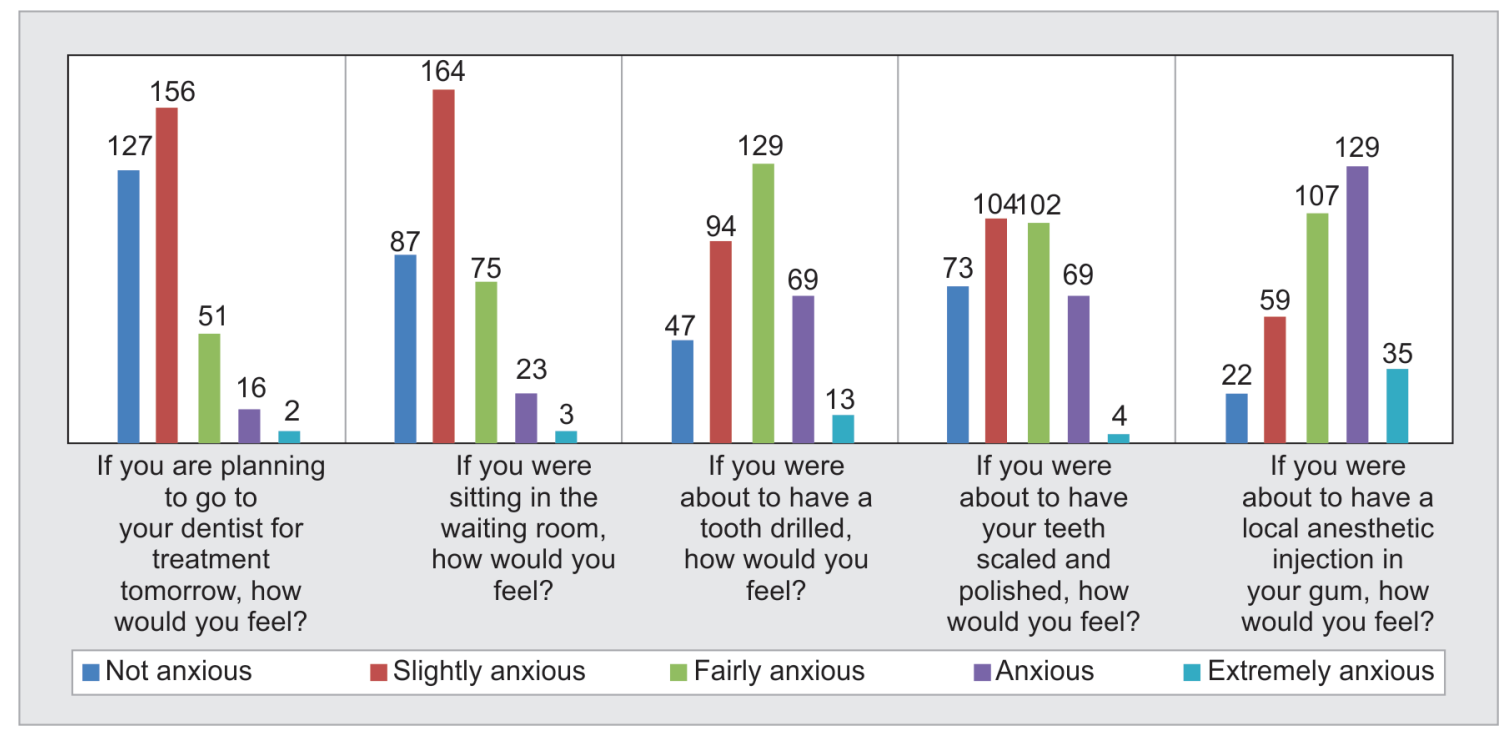

Fig. 2: The distribution of subjects according responses to the items of MDAS $(n=352)$ 
Dental Anxiety and Khat Chewing

Table 2: Association between genders and the type of first dental treatment, irregular dental visit, and causes of anxiety

\begin{tabular}{|c|c|c|c|c|c|c|c|}
\hline \multirow{2}{*}{$\begin{array}{l}\text { Variable } \\
\text { Gender }\end{array}$} & \multicolumn{6}{|c|}{ Type of first dental treatment } & \multirow[b]{2}{*}{ pvalue } \\
\hline & Surgery & Endodontic & Periodontal & Restoration & \multicolumn{2}{|r|}{ Ortho/prosthetic } & \\
\hline Male $n(\%)$ & $61(22.9)$ & $90(33.8)$ & $67(25.2)$ & $39(14.7)$ & \multicolumn{2}{|r|}{$9(3.4)$} & \multirow[t]{3}{*}{$0.000^{*}$} \\
\hline Female $n(\%)$ & $20(23.3)$ & $12(14.0)$ & $14(16.3)$ & $18(20.9)$ & \multicolumn{2}{|r|}{$22(25.4)$} & \\
\hline Total & $81(23.0)$ & $102(29.0)$ & $81(23.0)$ & $57(16.2)$ & \multicolumn{2}{|r|}{$31(8.8)$} & \\
\hline Variable & \multicolumn{6}{|c|}{ Causes of irregular dental visit } & \multirow[b]{2}{*}{$p$ value } \\
\hline Gender & \multicolumn{2}{|c|}{ Fear } & Time & Cost & \multicolumn{2}{|r|}{ No specific cause } & \\
\hline Male $n(\%)$ & \multicolumn{2}{|c|}{$112(42.1)$} & $44(16.5)$ & $67(21.5)$ & \multicolumn{2}{|r|}{$53(14.9)$} & $0.013^{*}$ \\
\hline Female $n(\%)$ & \multicolumn{2}{|c|}{$28(32.6)$} & $22(25.6)$ & $10(11.6)$ & \multicolumn{2}{|r|}{$26(30.2)$} & \\
\hline Total & \multicolumn{2}{|c|}{$140(39.8)$} & $66(18.8)$ & $77(19.0)$ & \multicolumn{2}{|r|}{$79(22.4)$} & \\
\hline Variable & \multicolumn{6}{|c|}{ What made you anxious } & \\
\hline Gender & Fear of pain & Dental chair & Equipment & Injection & Drills & Dental staff & $p$ value \\
\hline Male $n(\%)$ & $74(27.8)$ & $9(3.4)$ & $16(9.0)$ & $112(42.1)$ & $54(20.3)$ & $1(0.4)$ & 0.197 \\
\hline Female $n(\%)$ & 29 (33.7) & $2(2.3)$ & $8(9.3)$ & $35(40.7)$ & $10(11.6)$ & $2(2.3)$ & \\
\hline Total & $103(29.3)$ & $11(3.1)$ & $24(6.8)$ & $147(41.8)$ & 64 (18.2) & $3(0.9)$ & \\
\hline
\end{tabular}

*Significant differences

Table 3: Association between khat chewing groups and type of first dental treatment, irregular dental visit, and cause of anxiety

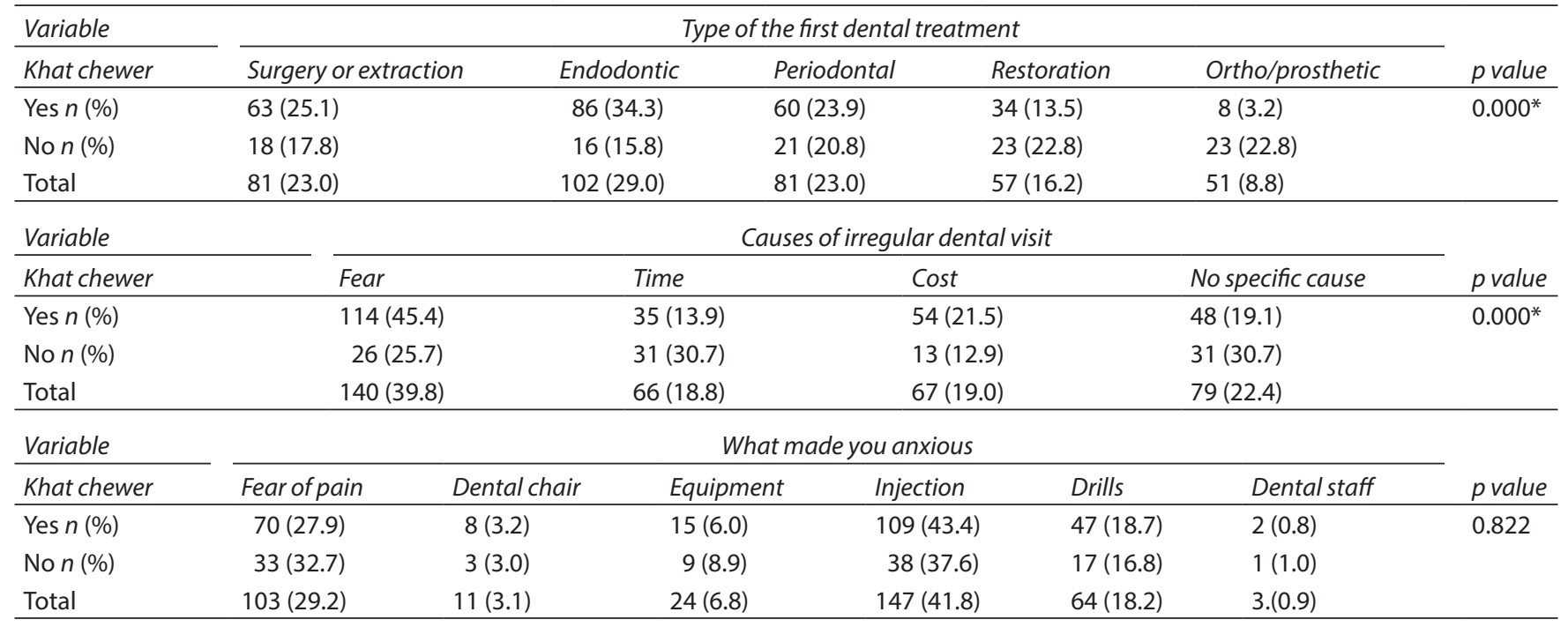

*Significant differences

followed by surgery and periodontal treatments and registered as $34.3 \%, 25.1 \%$, and $23.9 \%$, respectively. Among non-khat chewer subjects, an equal percentage (22.8) was registered in relation to restorative, prosthodontics, and orthodontic treatments. The highest percentage of irregular dental visits was high due to the fear of dental treatments, i.e., 45.4 among khat chewers. But for non-khat chewers, an equal percentage 30.7 was found due to lack of time and no specific reasons. It was highly significant with $p$ value of 0.000 . The highest percentage was related to injection, i.e., 43.3 among khat chewers and 37.6 among non-khat chewers followed by fear of pain among khat chewers $27.9 \%$ and non-khat chewers $32.7 \%$, and it was not significant with $p$ value of 0.822 (Table 3).

For MDAS items, the order of the high frequency and percentage of the fairly anxious situation of all the dental treatments was in items of tooth drilling followed by local anesthesia injection, and having teeth scaled and polished with 129 and 36.6, 107 and 30.4 , and 102 and 29.0, respectively. Anxious item was high during local anesthesia injection 129 (36.6\%) (Fig. 2).
Table 4 shows the association between MDAS and genders. In males, the highest frequency and percentage were related to fairly anxious and anxious conditions and were also related to items/ situation of the dental treatments which included the tooth drilling 111 and 41.7 and 59 and 22.2, polishing of teeth 94 and 35.3 and 64 and 24.1, and local anesthesia injection in the gum 87 and 32.7 and 105 and 39.5, respectively. But among females the highest frequency and percentages were related to anxious, fairly anxious, and extremely anxious and recorded 24 and 27.9, 20 and 23.3, and 19 and 22.1, respectively. The DA levels are significantly different between male and female, with $p$ value $\geq 0.050$ (Table 4).

The association between khat chewing and DA level is presented in Table 5. Among the khat chewers, the highest frequency and percentage score were related to the fairly anxious and were related to the feeling of the dental treatments with regard to tooth drilling 106 and 42.2, polishing of teeth 88 and 35.1, and local anesthesia injection in the gum 85 and 33.9, respectively. Also, it reaches anxious condition during injection of local anesthesia 
Table 4: Association between MDAS items and gender $(n=352)$

\begin{tabular}{|c|c|c|c|c|c|c|}
\hline Gender/MDAS & Not anxious $n(\%)$ & $\begin{array}{l}\text { Slightly } \\
\text { anxious n (\%) }\end{array}$ & $\begin{array}{l}\text { Fairly } \\
\text { anxious n (\%) }\end{array}$ & Anxious n (\%) & $\begin{array}{l}\text { Extremely } \\
\text { anxious n (\%) }\end{array}$ & p value \\
\hline \multicolumn{7}{|c|}{ If you are planning to go to your dentist for treatment tomorrow, how would you feel? } \\
\hline Male & $76(28.6)$ & $137(51.5)$ & $40(15.0)$ & $13(4.9)$ & $0(0.0)$ & \multirow[t]{2}{*}{$0.000^{*}$} \\
\hline Female & $51(54.3)$ & $19(22.1)$ & $11(12.8)$ & $3(3.5)$ & $2(2.3)$ & \\
\hline \multicolumn{7}{|c|}{ If you were sitting in the waiting room, how would you feel? } \\
\hline Male & $55(20.7)$ & $126(47.4)$ & $66(24.8)$ & $18(6.8)$ & $1(0.04)$ & \multirow[t]{2}{*}{$0.002^{*}$} \\
\hline Female & $32(37.2)$ & $38(44.2)$ & $9(10.5)$ & $5(5.8)$ & $2(2.3)$ & \\
\hline \multicolumn{7}{|c|}{ If you were about to have a tooth drilled, how would you feel? } \\
\hline Male & $28(10.5)$ & $65(24.4)$ & $111(41.7)$ & $59(22.2)$ & $3(1.1)$ & \multirow[t]{2}{*}{$0.000^{*}$} \\
\hline Female & $19(22.1)$ & $29(33.7)$ & $18(20.9)$ & $10(11.6)$ & $10(11.6)$ & \\
\hline \multicolumn{7}{|c|}{ If you were about to have your teeth scaled and polished, how would you feel? } \\
\hline Male & $39(14.7)$ & $69(25.9)$ & $94(35.3)$ & $64(24.1)$ & $0(0.0)$ & \multirow[t]{2}{*}{$0.000^{*}$} \\
\hline Female & $34(39.5)$ & $35(40.7)$ & $8(9.3)$ & $5(5.8)$ & $4(4.7)$ & \\
\hline \multicolumn{7}{|c|}{ If you were about to have a local anesthetic injection in your gum, how would you feel? } \\
\hline Male & $14(5.3)$ & $44(16.5)$ & $87(32.7)$ & $105(39.5)$ & $16(6.0)$ & \multirow[t]{2}{*}{$0.000^{*}$} \\
\hline Female & $8(9.3)$ & $15(17.4)$ & $20(23.3)$ & $24(27.9)$ & $19(22.1)$ & \\
\hline
\end{tabular}

*Significant differences

102 and 40.6. In non-khat chewers, the highest frequency and percentages were related to anxious 27 and 26.7 , followed by fairly anxious 23 and 22.8 and were related to tooth drilling and injection of local anesthesia. A significantly different values were recorded between khat and non-khat chewers, with $p$ value $\geq 0.050$.

\section{Discussion}

Dental anxiety is the major and the most common cause of fear that can eventually lead to avoidance and irregular visits of dental care. ${ }^{5,33}$ Khat-chewing habit is prevalent among adult subjects of Jazan population in Kingdom of Saudi Arabia. ${ }^{17}$ Khat is a stimulant of central nervous system and is believed to progress work capacity, tolerate traveling, and counter fatigue among students while preparing for their examination. ${ }^{28,29}$ Globally, studies from around the world documented a psychological effect with a high prevalence of moderate symptoms of anxiety and stress among university students who chew khat regularly. ${ }^{28,29,36}$

We used the MDAS in the current study to assess the DA level, because it is considered as being valid, reliable, brief, accessible, and easy to use. We offered some assistance to participants for solving problems faced during scoring and screening the examination sheets. The purpose of the present study was to investigate and compare the levels of DA among khat and non-khat chewer subjects of both gender from Jazan city, Kingdom of Saudi Arabia.

Overall, the mean scores of DA for the groups indicated in the present study were not dentally anxious at all or were mildly dentally anxious. The score of MDAS among all participants were $40 \%$ and $38 \%$, which categorized as having a low and moderate levels of DA. These results are in agreement with the findings recorded by Al Bahhawi et al., Almalik et al., Alalwan et al., and Suhani et al., 4,16,17,19 i.e., all recorded the same level of DA. Even though our results may coincide with the high DA level published by Al-Khalifa, Gaffar et al., Alatram, Fayad et al., and Ibrahim et al., $5,9,12,15,20$ we calculated $18 \%$ of our participants with high level of DA. Because most of our recruited subjects were khat chewers, it is not surprising to register dental phobia as $8.1 \%$ in our samples, which is equal to $8 \%$ mentioned by Al Jasser et al. ${ }^{33}$ and considered as a high percentage as compared to $5.3 \%$ by Suhani et al. ${ }^{16}$ and near to $10.5 \%$ registered by Inamdar et al. ${ }^{21}$ and Ibrahim et al. (Fig. 1). ${ }^{20}$

From Tables 2 and 3, regarding the type of the first dental treatment, among the participants of the current study, the endodontic treatments registered the high frequency and percentages in both male and female, i.e., 102 and 29, as well as among khat and non-khat chewers 102 and 29. This is in agreements with the findings of Al-Khalifa, Al-Dosari, and Alaki et al., 5,22 but did not match the findings of, Gaffar et al., Alaki et al., Al-Madi and AbdelLatif, and Al-Namankany et al., 9,22,37,38 who found that dental extraction was the first type of dental treatments among their tested samples. But all results including ours found that fear alone or fear combined with pain is the main cause of irregular dental visits and the causes make the participant a dentally anxious patient, according to Al Jasser et al. and Ibrahim et al. ${ }^{20,33}$ Lower percentages were registered during periodontal and prophylaxis treatments as documented by Al-Madi and AbdelLatif, ${ }^{37}$ while Gaffar et al. ${ }^{9}$ had found that lack of time was the highest cause of irregular dental treatments. In addition, Suhani et al. ${ }^{16}$ demonstrated all causes together were the major causes of dental visits.

In most studies, they found that prevalence and percentage of DA is higher among females when compared with males Al Bahhawi et al., Sghaireen et al., Al-Khalifa, Gaffar et al., Suhani et al., Caltabiano et al., Ibrahim et al., Alaki et al. ${ }^{5,9,10,14,16,17,20,22}$ Those findings are in disagreement with the results of our finding, which could be related to the small sample size of female in our study 86 (24.4\%) (Table 1). But our findings were in parallel and coincided with Al-Dosari et al., Almalik et al., Allam et al., Hakami et al., 6,13,18,19 i.e., these concluded that males are higher in DA. Even though the findings of this study revealed that both genders had a slight anxious or anxious level of DA, both groups' scores indicate they were not dentally anxious at all (Table 4).

Khat chewing may be associated with anxiety, increased heart rate, and depression. ${ }^{17}$ This was quite obvious in our results related to khat chewer groups, which register significant differences when compared to non-khat chewers. In addition to that the khat-chewing group recorded as fairly anxious, anxious, and extremely anxious with a high percentage in the five items of MDAS (Table 5). 
Table 5: Association between MDAS items and khat chewing $(n=352)$

\begin{tabular}{|c|c|c|c|c|c|c|}
\hline MDAS/khat chewer & Not anxious $n(\%)$ & $\begin{array}{l}\text { Slightly } \\
\text { anxious n (\%) }\end{array}$ & $\begin{array}{l}\text { Fairly } \\
\text { anxious n (\%) }\end{array}$ & Anxiousn (\%) & $\begin{array}{l}\text { Extremely } \\
\text { anxious } n(\%)\end{array}$ & $p$ value \\
\hline \multicolumn{7}{|c|}{ If you are planning to go to your dentist for treatment tomorrow, how would you feel? } \\
\hline Yes (khat chewer) & $69(27.5)$ & $134(53.4)$ & $37(14.7)$ & $11(4.4)$ & $0(0.0)$ & \multirow[t]{2}{*}{$0.000^{*}$} \\
\hline No & $56(57.4)$ & $22(21.8)$ & $14(13.9)$ & $5(5.0)$ & $2(2.0)$ & \\
\hline \multicolumn{7}{|c|}{ If you were sitting in the waiting room, how would you feel? } \\
\hline Yes (khat chewer) & $51(20.3)$ & $122(48.6)$ & $58(23.1)$ & $20(8.0)$ & $0(0.0)$ & \multirow[t]{2}{*}{$0.001^{*}$} \\
\hline No & $36(35.6)$ & $42(41.6)$ & $17(16.8)$ & $3(3.0)$ & $3(3.0)$ & \\
\hline \multicolumn{7}{|c|}{ If you were about to have a tooth drilled, how would you feel? } \\
\hline Yes (khat chewer) & $26(10.4)$ & $55(21.9)$ & $106(42.2)$ & $62(24.7)$ & $2(0.8)$ & \multirow[t]{2}{*}{$0.000^{*}$} \\
\hline No & $21(20.8)$ & $39(38.6)$ & $23(22.8)$ & $7(6.9)$ & $11(10.9)$ & \\
\hline \multicolumn{7}{|c|}{ If you were about to have your teeth scaled and polished, how would you feel? } \\
\hline Yes (khat chewer) & $38(15.1)$ & $67(26.7)$ & $88(35.1)$ & $57(22.7)$ & $1(0.4)$ & \multirow[t]{2}{*}{$0.000^{*}$} \\
\hline No & $35(34.7)$ & $37(36.6)$ & $14(13.9)$ & $12(11.9)$ & $3(3.0)$ & \\
\hline \multicolumn{7}{|c|}{ If you were about to have a local anesthetic injection in your gum, how would you feel? } \\
\hline Yes (khat chewer) & $10(4.0)$ & $38(15.1)$ & $85(33.9)$ & $102(40.6)$ & $16(6.4)$ & \multirow[t]{2}{*}{$0.000^{*}$} \\
\hline No & $12(11.9)$ & $21(20.8)$ & $22(21.8)$ & $27(26.7)$ & $9(8.8)$ & \\
\hline
\end{tabular}

*Significant differences

An interesting point to be noted when examining the subjects in relation to the items of MDAS. As mentioned by previous studies, dental injections in the gum alone or with tooth drillings were the most items causing DA as found by Inamdar et al., Al-Towayan and Osman, Al-Khalifa, Gaffar et al., Fayad et al., and Alaki et al., 5,7, 15,21,22 and this is in total agreements with our record, i.e., among both genders and participants with or without khat-chewing habit.

Since the present study has been conducted on limited subjects who attended dental clinics during the study period, which may be considered as a limitation. Those patients may have different demographic and lower socioeconomic status levels; therefore, studies on larger subjects from different types of clinics with different age-groups are needed to reveal prevalence and enormity of DA in the examined society. Also, further studies with different designs should be accomplished to investigate the different commencing factors of DE. In addition, in the khat-chewing group, the period of chewing hours per day, months, and years were not considered.

\section{ConCLUSION}

Within the scope of the current cross-sectional study, the following conclusion can be drawn:

- The overall DA level is low and moderate among the majority of the involved subjects.

- Endodontic treatment was recorded as the highest in frequency and percentage as a first type of dental treatment among the participants, while fear of pain is the most common cause of irregular dental visits.

- Local anesthesia injection in the gum, followed by drilling of teeth are the most items of the MDAS that cause DA among both genders and khat and non-khat chewer groups.

- Significant differences were detected among both genders and khat and non-khat chewer groups in the all items of DA.

\section{References}

1. Freeman R. The psychology of dental patient care: Barriers to accessing and accepting dental care. Br Dent J 1999;187(2):81-84. DOI: $10.1038 /$ sj.bdj.4800208.

2. Armfield JM. How do we measure dental fear and what are we measuring anyway? Oral Health Prev Dent 2010;8(2):107-115.
3. Cappelli DP, Mobley CC. Prevention in Clinical Oral Health Care-EBook. Elsevier Health Sciences; 2007.

4. Alalwan SAM, Albader FNB, Alkhalaf ZAH, et al. Dental anxiety among patients undergoing different dental treatments in College of Dentistry, Riyadh Elm University. Saudi J Oral Dent Res 2018;3(12): 379-385. DOI: 10.21276/sjodr.2018.3.12.2.

5. Al-Khalifa KS. Prevalence of dental anxiety in two major cities in the Kingdom of Saudi Arabia. Saudi J Med Med Sci 2015;3(2):135-140. DOI: 10.4103/1658-631X.156421.

6. Allam R, Allam Y, Al-Samhan A, et al. Gender differences in anxiety levels about dentistry in Saudi dental college students. EC Dent Sci 2018;17(6):663-667.

7. Al-Towayan A, Osman KH. Prevalence of dental anxiety among medical and dental undergraduates in Gassim University. Prevalence 2018;4(3):15-18.

8. Duko B, Gebeyehu A, Ayano G. Prevalence and correlates of depression and anxiety among patients with tuberculosis at WolaitaSodo University Hospital and Sodo Health Center, WolaitaSodo, South Ethiopia, cross sectional study. BMC Psychiatry 2015;15(1):214. DOI: 10.1186/s12888-015-0598-3.

9. Gaffar BO, Alagl AS, Al-Ansari AA. The prevalence, causes, and relativity of dental anxiety in adult patients to irregular dental visits. Saudi Med J 2014;35(6):598-603.

10. Sghaireen MG, Zwiri A, Alzoubi IA, et al. Anxiety due to dental treatment and procedures among university students and its correlation with their gender and field of study. Int J Dent 2013;2013:647436. DOI: 10.1155/2013/647436.

11. Alafaleg R, Buraidah Q. Prevalence of dental anxiety among Saudi population in Buraiydah. Dent Studs' Res 2014;1:24-32

12. Alatram A. Assessment of pre and post dental treatment anxiety among Saudi Arabian population. Majmaah J Health Sci 2014;216(1217):1-10. DOI: 10.12816/0004780.

13. Al-Dosari A. Dental fear among visitors of primary health care centers in Saudi Arabia. Trop Dent J 1996;11:9.

14. Caltabiano ML, Croker F, Page L, et al. Dental anxiety in patients attending a student dental clinic. BMC Oral Health 2018;18(1):48. DOI: 10.1186/s12903-018-0507-5.

15. Fayad MI, Elbieh A, Baig MN, et al. Prevalence of dental anxiety among dental patients in Saudi Arabia. J Int Soc Prev Community Dent 2017;7(2):100-104. DOI: 10.4103/jispcd.JISPCD_19_17.

16. Suhani RD, Suhani MF, Badea ME. Dental anxiety and fear among a young population with hearing impairment. Clujul Med 2016;89(1):143-149. DOI: 10.15386/cjmed-556. 
17. Al Bahhawi T, Albasheer OB, Makeen AM, et al. Depression, anxiety, and stress and their association with khat use: a cross-sectional study among Jazan University students, saudi arabia. Neuropsychiatr Dis Treat 2018;14:2755-2761. DOI: 10.2147/NDT.S182744.

18. Hakami RM, Mahfouz MS, Adawi AM, et al. Social anxiety disorder and its impact in undergraduate students at Jazan University, Saudi Arabia. Ment IIIn 2017;9(2):7274. DOI: 10.4081/mi.2017.7274.

19. Almalik M, Alnowaiser A, El Meligy O, et al. Clinical anxiety among Saudi postgraduate pediatric dentistry students in Jeddah City. Int J Dent 2018;2018:5863869. DOI: 10.1155/2018/5863869.

20. Ibrahim NK, Al-Jdani M, Al-Aamoudi N, et al. Anxiety due to dental procedures and treatment among adult patients attending outpatient clinics in King Abdulaziz University Hospital, Jeddah, Saudi Arabia. J Med Res 2016;2(2):35-40.

21. Inamdar A, Alwadaani M, Asiri A, et al. Dental anxiety in medical and dental undergraduates at Jazan University. J Oral Health Res 2014;4(3):25-30.

22. Alaki S, Alotaibi A, Almabadi E, et al. Dental anxiety in middle school children and their caregivers: prevalence and severity. J Dent Oral Hyg 2012;4(1):6-11. DOI: 10.5897/JDOH11.019.

23. Al-Sowygh ZH, Alfadley AA, Al-Saif Ml, et al. Perceived causes of stress among Saudi dental students. King Saud Univ J Dent Sci 2013;4(1):7-15. DOI: 10.1016/j.ksujds.2012.11.002.

24. Dailey YM, Humphris GM, Lennon MA. The use of dental anxiety questionnaires: a survey of a group of UK dental practitioners. $\mathrm{Br}$ Dent J 2001;190(8):450-453. DOI: 10.1038/sj.bdj.4801000.

25. Coolidge T, Arapostathis KN, Emmanouil D, et al. Psychometric properties of greek versions of the modified corah dental anxiety scale (MDAS) and the dental fear survey (DFS). BMC Oral Health 2008;8(1):29. DOI: 10.1186/1472-6831-8-29.

26. Humphris G, Freeman R, Campbell J, et al. Further evidence for the reliability and validity of the modified dental anxiety scale. Int Dent J 2000;50(6):367-370. DOI: 10.1111/j.1875-595x.2000.tb00570.x.

27. Al-Alimi KR, Razak AAA, Saub R. Is Khat chewing habit a risk factor for occlusal caries progression? Afr Health Sci 2018;18(4):1036-1045. DOI: $10.4314 / a h s . v 18 \mathrm{i} 4.25$.
28. Yeshaw Y, Mossie A. Depression, anxiety, stress, and their associated factors among Jimma University staff, Jimma, Southwest Ethiopia, 2016: a cross-sectional study. Neuropsychiatr Dis Treat 2017;13:28032812. DOI: $10.2147 /$ NDT.S150444.

29. Odenwald M, Neuner F, Schauer M, et al. Khat use as risk factor for psychotic disorders: a cross-sectional and case-control study in Somalia. BMC Med 2005;3:5. DOI: 10.1186/1741-7015-3-5.

30. Patel SL. Attitudes to khat use within the Somali community in England. Drugs Educ Prev Policy 2008;15(1):37-53. DOI: 10.1080/09687630601138691.

31. do Nascimento DL, da Silva Araújo AC, Gusmão ES, et al. Anxiety and fear of dental treatment among users of public health services. Oral Health Prev Dent 2011;9(4):329-337.

32. Al Moaleem MM, Porwal A, Al Ahmari NM, et al. Khat chewing induces a floral shift in dental naterial-associated microbiota: a preliminary study. Med Sci Monit 2020;26:e918219. DOI: 10.12659/MSM.918219.

33. Al Jasser RA, Almashaan $\mathrm{G}$, Alwaalan $\mathrm{H}$, et al. Dental anxiety among dental, medical, and nursing students of two major universities in the central region of the Kingdom of Saudi Arabia: a cross-sectional study. BMC Oral Health 2019;19(1):56. DOI: 10.1186/s12903-019-0757-x.

34. Al-Namankany A, Ashley P, Petrie A. Development of the first Arabic cognitive dental anxiety scale for children and young adults. World J Meta-Anal 2014;2(3):64-70. DOI: 10.13105/wjma.v2.i3.64.

35. Al-Nasser L, Yunus F, Ahmed A. Validation of Arabic version of the modified dental anxiety scale and assessment of cut-off points for high dental anxiety in a Saudi population. J Int Oral Health 2016;8(1):21.

36. Singh M, Goel NK, Sharma MK, et al. Prevalence of depression, anxiety and stress among students of Punjab University, Chandigarh. Age 2017;86(211):52-58.

37. Al-Madi EM, AbdelLatif $\mathrm{H}$. Assessment of dental fear and anxiety among adolescent females in Riyadh, Saudi Arabia. Saudi Dent J 2002;14(2):77-81.

38. Al-Namankany A. Assessing dental anxiety in young girls in KSA. J Taibah Univ Med Sci 2018;13(2):123-128. DOI: 10.1016/ j.jtumed.2017.11.005. 
Dental Anxiety and Khat Chewing

\begin{tabular}{|c|c|c|c|c|c|c|c|c|}
\hline \multicolumn{9}{|c|}{ Dental anxiety questionnaire } \\
\hline \multicolumn{9}{|l|}{ Part I } \\
\hline Gender & \multicolumn{2}{|l|}{ Male } & \multicolumn{6}{|c|}{ Female } \\
\hline \multicolumn{9}{|l|}{ Job } \\
\hline Patient treated in & \multicolumn{2}{|c|}{ Private clinics } & \multirow{2}{*}{\multicolumn{3}{|c|}{ Governmental and military clinics }} & \multicolumn{3}{|l|}{ University clinics } \\
\hline \multicolumn{6}{|l|}{ Age } & & & \\
\hline Marital status & \multicolumn{2}{|l|}{ Single } & \multicolumn{3}{|c|}{ Married } & \multicolumn{3}{|l|}{ Divorced } \\
\hline Education & \multicolumn{2}{|c|}{ Not educated } & \multicolumn{3}{|c|}{ High school } & \multicolumn{2}{|c|}{ University degree and diploma } & Postgraduate study \\
\hline Monthly income & \multicolumn{2}{|c|}{ Up to 3,000} & \multicolumn{3}{|c|}{$3,000-10,000$} & \multicolumn{2}{|l|}{$10,000-19,000$} & More than 20,000 Riyals \\
\hline Khat chewer & \multicolumn{2}{|l|}{ Yes } & \multicolumn{5}{|l|}{ No } & \\
\hline \multicolumn{9}{|l|}{ Part II } \\
\hline \multicolumn{2}{|c|}{ Type of first dental treatment } & \multicolumn{3}{|c|}{ Surgery and extraction } & ENDO & $\begin{array}{l}\text { Perio treatment } \\
\text { in form of scaling, } \\
\text { polishing, and root } \\
\text { planning }\end{array}$ & RSTO & ORTHO \\
\hline \multirow{2}{*}{\multicolumn{2}{|c|}{$\begin{array}{l}\text { Causes of irregular dental visit } \\
\text { What made you anxious? }\end{array}$}} & \multicolumn{3}{|c|}{ Fear } & Time & Cost & \multicolumn{2}{|c|}{ No specific cause } \\
\hline & & Fea & f pain & Dental chair & Equipment & Injections & Drills & Dental person \\
\hline
\end{tabular}

\section{Part III modified dental anxiety scale}

\begin{tabular}{|c|c|c|c|c|c|}
\hline Question MDAS & $\begin{array}{l}\text { Not } \\
\text { anxious }\end{array}$ & $\begin{array}{l}\text { Slightly } \\
\text { anxious }\end{array}$ & $\begin{array}{l}\text { Fairly } \\
\text { anxious }\end{array}$ & Anxious & $\begin{array}{l}\text { Extremely } \\
\text { anxious }\end{array}$ \\
\hline \multicolumn{6}{|l|}{ If you go to your dentist for treatment tomorrow, how would you feel? } \\
\hline \multicolumn{6}{|l|}{ If you were sitting in the waiting room, how would you feel? } \\
\hline \multicolumn{6}{|l|}{ If you were about to have a tooth drilled, how would you feel? } \\
\hline \multicolumn{6}{|l|}{ If you were about to have your teeth scaled and polished, how would you feel? } \\
\hline If you were about to have a local anesthetic injection in your gum, how would you feel? & & & & & \\
\hline
\end{tabular}

